\title{
Malaria and HIV Infection among Febrile Patients in a Large Area of Southwestern Nigeria
}

\author{
Oyetunde T. Oyeyemi', Edet J. Etim² \\ 1 Department of Biological Sciences, University of Medical Sciences, Ondo, Nigeria \\ 2 Department of Biosciences and Biotechnology, Babcock University, Ilishan-Remo, Ogun State, Nigeria
}

\section{CORRESPONDENCE \\ Oyetunde Oyeyemi \\ University of Medical Sciences \\ Laje Road, Ondo, Nigeria \\ Tel: +2348163546787 \\ E-mail: zootund@yahoo.com, \\ ooyeyemi@unimed.edu.ng}

\section{ARTICLE HISTORY}

Received: April 18, 2020

Accepted: May 16, 2020

\begin{abstract}
Background: Malaria and HIV/AIDS are two major diseases that represent serious public health threats in Nigeria. They have been ascribed diseases of poverty, and therefore their distribution is expected to be overlapping. Aim: The aim of this study was to determine the prevalence of malaria parasites and HIV among febrile patients in the Ikeja area of Lagos State, Nigeria. Materials and Methods: The study was conducted on 300 patients attending medical consultation and referred to blood screening for malaria parasites at Reddington Hospital, Lagos State. Malaria parasites were identified microscopically, and HIV screening was carried out using rapid diagnostic tests (RDT). Results: The prevalence of malaria and HIV was $98.7 \%$ and 3.7\%, respectively. All HIV-positive individuals were also infected by malaria parasites. Mean parasitemia was significantly higher in HIV-positive individuals (16,507.9 $\pm 2,280.7 \mathrm{P} / \mu \mathrm{L})$ than in HIV-negative subjects $(3,252.505 \pm 236.3 \mathrm{P} / \mu \mathrm{L})(p<0.05)$. Conclusions: Our results suggest that HIV-infected individuals are more susceptible to infection with malaria parasites. Prompt HIV management is necessary in malaria-endemic areas to reduce disease severity in case of coinfection with HIV.
\end{abstract}

Keywords: malaria, HIV/AIDS, association, morbidity, Nigeria

\section{BACKGROUND}

Malaria and HIV/AIDS are two major diseases with serious public health implications in Nigeria. Globally, Nigeria is ranked number one and two in the total number of people affected by malaria and HIV/AIDS, respectively. ${ }^{1,2}$ Both diseases are poverty-related, as the poorest segment of the population is the most vulnerable due to the lack of access to information, quality education, and good health facilities. ${ }^{3}$ Each year, malaria and HIV cause over 2 million deaths globally. ${ }^{4}$ Children under the age of 5 and pregnant women have the highest morbidity associated with malaria parasites infection, ${ }^{5,6}$ while women and adolescent girls have the highest risk of HIV infection. ${ }^{7}$ During concurrent malaria parasites and HIV infections, approximately 1 million pregnant women experience vari- 
ous degrees of complications in countries of sub-Saharan Africa, ${ }^{8}$ thus endangering the lives of both the mothers and the fetuses.

The geographical overlap between malaria parasites and HIV infections has generated research interest in terms of co-morbidity impact of concomitant infections. Some studies have suggested that there is no association between malaria parasites and HIV infection, ${ }^{9}$ especially in populations where the prevalence of HIV is low. ${ }^{10}$ However, others have reported a bidirectional and synergistic interaction. ${ }^{11}$ Evidence has implicated concomitant malaria parasite and HIV infection in facilitating the progression of malaria. Importantly, malaria and HIV coinfection has been linked to an increased risk of severe malaria in adults, congenital infection, and increased transmission dynamics of the two diseases. ${ }^{12-14}$ On the other hand, malaria has been reported to cause a reduction in $\mathrm{CD} 4$ cell count, thus exacerbating the clinical course of those infected with HIV. ${ }^{15}$ Another study showed a significant rise in HIV-1 plasma load in individuals infected with malaria parasites compared to those without infection, even after up to 10 weeks of treatment. ${ }^{16}$ Factors influencing the clinical impact of these interactions could include extent of malaria transmission in the area, host immunity, and the individual affected (e.g., adult, child, or pregnant woman). ${ }^{17}$

The aim of this study was to determine the prevalence of malaria and HIV among febrile patients in the Ikeja area of Lagos State, Nigeria. The study also sought to gather more evidence on the susceptibility of individuals to malaria parasites infection in case of concomitant infection with HIV.

\section{MATERIALS AND METHODS}

The study was carried out in Ikeja, a city with a population of about 437,400 people, located in Lagos State, Nigeria. The city is close to the popular Murtala Muhammad International Airport. It is the capital of Lagos State with a very large residential zone, and it is set near the Lagos Lagoon. There were over 60,000 cases of malaria in Ikeja in 2013.18 The closeness of the city to Lagos Lagoon and the poor drainage system found in some of its areas could provide suitable breeding sites for mosquito malaria parasite vectors, enabling stable transmission of malaria. As far as HIV/AIDS is concerned, its transmission is largely associated with large population sizes and fluid movement of people in and out of the state. ${ }^{19}$

A descriptive cross-sectional study was conducted among febrile patients who presented themselves for medical examination at Reddington Hospital, one of the many hospitals in Ikeja receiving malaria patients. To calculate our sample size, we used the prevalence of malaria and HIV coinfection (2.9\%) previously reported in Ikeja, ${ }^{20}$ and a precision $(d)$ of $2 \%$. Using the method of Daniel, ${ }^{21}$ a minimum sample size of approximately 270 participants was calculated. The study included 300 subjects, regular dwellers of the area or Lagos. Only febrile patients with signs and symptoms of uncomplicated malaria, such as fever $\geq 40^{\circ} \mathrm{C}$, chill, headache, rigor, and joint pain, were included. ${ }^{22}$

Venous blood samples were obtained from the subjects by a trained laboratory staff on duty. Clean and grease-free labeled glass slides were prepared, and then thick and thin blood films were made by spreading a drop of blood on the slides. The blood was allowed to dry and then stained with $10 \%$ Giemsa stain solution. After $10 \mathrm{~min}$, the stain was washed with clean running water and then dried. A drop of immersion oil was applied to each slide and was examined under $\times 100$ objective lens for malaria parasites. Parasitemia was estimated using the methods described by Cheesbrough. ${ }^{23}$

All subjects were screened using Determine (DT) HIV$1 / 2$ test kits (Alere Medical Company Limited, Chiba, Japan). About 3-5 $\mathrm{mL}$ of blood was collected by venipuncture and transferred to an EDTA bottle. The blood was properly mixed and then centrifuged at 1,500 rpm for $10 \mathrm{~min}$. The plasma was stored in a plain tube and kept at $-20^{\circ} \mathrm{C}$ until used. For testing, $50 \mu \mathrm{L}$ of the plasma was added to the test spot on the kit, and the result was read after $15 \mathrm{~min}$. The result was interpreted according to the kit instructions.

All kits were purchased centrally and were stored at the temperature specified by the manufacturer. Malaria and HIV tests were performed independently and were confirmed by another trained personnel. Participation in the study was voluntary, and only those who gave their consent were included. Children were included based on their parents' consent. Institutional ethical approval was obtained from Olabisi Onabanjo University Teaching Hospital (OOUTH), Ogun State, Nigeria.

Data were analyzed using SPSS for Windows version 22.0 (IBM Corp, Armonk, NY, USA). Counts and percentages were used to summarize categorical variables, and the mean \pm SE was used to summarize numerical variables. Differences in prevalence by subject categories were analyzed using the chi-square and Fisher's exact test, while malaria parasitemia was analyzed using one-way ANOVA. Tukey's post-hoc test was used to compare significant differences between groups. Significant differences in malaria parasitemia in relation to the participant's HIV status was tested using Student's $t$-test. A $p$ value less than 0.05 (p $<0.05$ ) was considered statistically significant. 
TABLE 1. Characteristics of the subjects

\begin{tabular}{lcc}
\hline Variables & Number & Proportion (\%) \\
\hline Age & & \\
$\quad$ Children (1-17 years) & 93 & 31.0 \\
Adults (18-59 years) & 160 & 53.3 \\
$\quad$ Elderly ( 260 years) & 47 & 15.7 \\
Gender & & \\
$\quad$ Male & 153 & 51.0 \\
Female & 147 & 49.0 \\
\hline
\end{tabular}

\section{RESULTS}

The study population comprised children ( $\mathrm{n}=93,1-17$ years; $31 \%$ ), adults ( $\mathrm{n}=160,18-59$ years; $53.3 \%$ ), and elderly subjects ( $\mathrm{n}=47, \geq 60$ years; $15.7 \%$ ) (Table 1 ). The mean age of the participants was $32.3 \pm 22.8$ years. The overall prevalence of malaria parasites was $98.7 \%$, and mean parasitemia was 3,695.2 \pm 281.2 parasites/ $\mu \mathrm{L}$ of blood $(\mathrm{P} /$ $\mu \mathrm{L})$. The prevalence of malaria in children (95.7\%) was not significantly different from that of adult $(100 \%)$ and elderly subjects $(100 \%)(\mathrm{p}>0.05)$. There was also no significant variation in the prevalence of malaria in male $(98.7 \%)$ and female subjects $(98.6 \%)$ ( $p>0.05)$. However, the intensity of infection due to malaria parasites varied significantly by age and gender $(\mathrm{p}<0.05)$. The mean parasitemia $(5,012.7 \pm$ 807.1 P/ $\mu \mathrm{L}$ ) of elderly subjects was significantly higher than that of adults $(4,273.0 \pm 424.7 \mathrm{P} / \mu \mathrm{L})$ and children $(2,035.1$ $\pm 287.4 \mathrm{P} / \mu \mathrm{L})(\mathrm{p}<0.05)$ (Table 2$)$. Also, male subjects had significantly higher parasitemia $(3,722.4 \pm 411.0 \mathrm{P} / \mu \mathrm{L})$ than female participants $(3,666.8 \pm 384.1 \mathrm{P} / \mu \mathrm{L})(\mathrm{p}<0.05)$.

The prevalence of HIV in the population was $3.7 \%$. Although the prevalence of HIV was higher in adults (5.6\%) than in the elderly (4.3\%) and in females (4.1\%) compared to males $(3.3 \%)$, the prevalence of HIV was neither agenor gender-dependent ( $\mathrm{p}>0.05$ ) (Table 3$)$. All HIV-positive subjects were infected with malaria parasites, while 98.6\% of HIV-negative individuals had malaria. Also, mean parasitemia was significantly higher in HIV-positive individuals $(16,507.9 \pm 2,280.7 \mathrm{P} / \mu \mathrm{L})$ than in HIV-negative subjects $(3,252.505 \pm 236.3 \mathrm{P} / \mu \mathrm{L})(\mathrm{p}<0.05)$.

\section{DISCUSSION}

The study has shown that malaria is still a major problem in Lagos despite all efforts put in place to curtail the spread of the disease. Generally, the prevalence of malaria is higher among febrile patients, and malaria is the most common cause of fever in Nigeria, especially in children. ${ }^{24}$ The prevalence reported in this study was the highest ever recorded in

TABLE 2. Prevalence and intensity of malaria parasite

\begin{tabular}{lcccc}
\hline Variables & $\begin{array}{c}\text { Number } \\
\text { examined }\end{array}$ & $\begin{array}{c}\text { Number } \\
\text { infected }\end{array}$ & $\begin{array}{c}\text { Proportion } \\
\mathbf{( \% )}\end{array}$ & $\begin{array}{c}\text { Parasitemia } \\
\mathbf{( P / \mu L )}\end{array}$ \\
\hline Age & & & & \\
$\quad$ Children (1-17 years) & 93 & 89 & 95.7 & $2,035.1 \pm 287.4^{\mathrm{a}}$ \\
$\quad$ Adults (18-59 years) & 160 & 160 & 100.0 & $4,273.0 \pm 424.7^{\mathrm{b}}$ \\
$\quad$ Elderly ( $\geq 60$ years) & 47 & 47 & 100.0 & $5,012.7 \pm 807.1^{\mathrm{c}}$ \\
$\begin{array}{l}\text { Gender } \\
\text { Male }\end{array}$ & 153 & 151 & 98.7 & $3,722.4 \pm 411.0^{\mathrm{a}}$ \\
$\quad$ Female & 147 & 145 & 98.6 & $3,666.8 \pm 384.1^{\mathrm{b}}$ \\
\hline
\end{tabular}

Different superscripts denote significant differences by Tukey's post-hoc test $(p<0.05)$. Similar superscripts denote no significant difference by Tukey's post-hoc test $(p>0.05)$.

TABLE 3. HIV status among febrile patients

\begin{tabular}{lcccc}
\hline Variables & $\begin{array}{c}\text { Number } \\
\text { examined }\end{array}$ & $\begin{array}{c}\text { Number } \\
\text { infected }\end{array}$ & $\begin{array}{c}\text { Proportion } \\
\text { (\%) }\end{array}$ & p value \\
\hline Age & 93 & 0 & 0.0 & 0.287 \\
$\quad$ Children (1-17 years) & 160 & 9 & 5.6 & \\
$\quad$ Adults (18-59 years) & 47 & 2 & 4.3 & \\
$\quad$ Elderly ( $\geq 60$ years) & 153 & 5 & 3.3 & 0.766 \\
Gender & 147 & 6 & 4.1 & \\
$\quad$ Male & 147 & & \\
$\quad$ Female & & & & \\
\hline
\end{tabular}


any region of Nigeria among febrile patients. Previous studies reported a prevalence of $7.4 \%$ in Ilorin, ${ }^{25} 29.7 \%$ in Oyo town, ${ }^{26}$ and $37.6 \%$ in Ikare-Akoko, Ondo. ${ }^{27}$ Higher prevalences of $54 \%,{ }^{28} 56 \%,{ }^{29} 63 \%,{ }^{30} 56.8 \%,{ }^{31}$ and $65.5 \%{ }^{32}$ were reported in Jos, Sokoto, Simawa Ogun State, Keffi, and Birnin Kudu in Kano State, respectively. In Lagos, our previous study found a prevalence of $39.5 \%, 61 \%$ and $61.3 \%$ among febrile infants, non-pregnant women, and pregnant women, respectively. ${ }^{22}$ Another study in Lagos reported a very high prevalence (92.1\%) among febrile infants (age $0-5$ years). ${ }^{24}$

This study confirmed that Lagos State is a suitable region for stable transmission of malaria. Evidence from the State's report on malaria cases showed that malaria transmission is far from being under control. Reports have shown an increase in malaria cases from 488,780 in 2012 to 547,150 in $2014 . .^{33}$ The probable reasons for this unabated increase in transmission include the presence of abundant water bodies in close proximity to human dwellings, suitable for the breeding of mosquitoes and subsequent transmission of malaria parasite to humans. Due to poor draining systems in many areas, this expanse of water bodies sometimes finds its way into canals and drainage systems, especially during flooding, to create further temporary breeding sites for these mosquitoes. Another possible reason could be the very low utilization of long-lasting insecticide-treated nets (LLIN) in Lagos, with a reported utilization rate of $18 \% .^{34}$ This value is significantly lower than the $59 \%$ and $67.6 \%$ LLIN utilization rates recorded in Osun and Ekiti State, respectively. ${ }^{34,35}$ Lagos is a megacity, and LLIN distribution through the government's malaria control program may pose some difficulties. In another study, adherence to current malaria treatment guidelines in Lagos was generally poor, as only $7 \%$ of people were using an artemisinin-based combined therapy in their last malaria episode; the majority of patients still preferred sulphadoxine-pyrimethamine and chloroquine. ${ }^{36}$ This could increase the development of resistant parasite strains, especially in the case of chloroquine.

Although there was no significant difference in the prevalence of malaria among different population groups, parasitemia varied significantly, with the older population carrying the higher burden of the disease. It is usually expected that children, especially infants, would bear the greatest burden of malaria, because acquired immunity may still be not well developed. However, advocacy for malaria prevention in children and pregnant women has been strong recently in Nigeria. This may yield a better adherence to malaria control in these groups. Even with limited resources, children (0-5 years) and pregnant women are given priority in malaria control programs in every state of Nigeria. These programs may have an impact by reducing the extent of exposure to mosquitoes and subsequently lowering the intensity of malaria parasites infection in these groups. Nevertheless, the mean parasitemia recorded in children was very high in our study, and efforts towards abating transmission should be further strengthened, not only in children, but also in the adult population (age 18-59 years) that has a significant number of pregnant women.

In our study, the prevalence of HIV was lower than in many studies reported elsewhere in Nigeria. A prevalence of $4.9 \%$ was reported in Osogbo, ${ }^{37} 6.2 \%$ in Abeokuta, ${ }^{38}$ $24.1 \%$ in Borno, ${ }^{39} 10 \%$ in Benin, and $16 \%$ in Zaria. ${ }^{40}$ The low prevalence we found in Lagos could represent the positive impact of the various HIV/AIDS prevention programs in the state. Of importance is the possible contribution of HIV infection to increasing susceptibility to malaria parasites infection. This was demonstrated by the increased prevalence and intensity of malaria parasites infection in HIV-positive subjects compared to HIV-negative individuals. While earlier studies have shown no relationship between HIV and the severity of malaria in children and adults, ${ }^{41,42}$ our results seem to confirm the findings of studies that have linked HIV infection to a predisposition to more frequent episodes of symptomatic and severe malaria. ${ }^{43}$ It is possible that by suppressing the immune system, HIV favors the multiplication and proliferation of malaria parasites.

\section{CONCLUSION}

This study has shown that malaria was hyperendemic among febrile patients, while HIV had a low incidence in Ikeja, Lagos. Due to the possible interactions between malaria and HIV/AIDS, the presence of one can influence the morbidity associated with the other. HIV increases susceptibility to malaria parasites and could therefore aggravate the burden associated with malaria in infected individuals, with more serious consequences in pregnant women and infants. In order to minimize the impact of HIV on malaria, malaria and HIV control programs should be integrated into one another. The distribution of LLIN and promotion of their usage should be incorporated into voluntary counselling and testing programs in malaria endemic areas. Prompt treatment of malaria confirmed febrile patients is also highly recommended, especially in HIV/AIDS endemic areas.

\section{ACKNOWLEDGEMENT}

The authors acknowledge the participants and the personnel on duty in Reddington Hospital, Ikeja, Lagos, Nigeria during data collection for their cooperation. 


\section{STATEMENT OF ETHICS}

Informed consent was obtained from the participants. Ethical approval with approval number OOUTH/DA.326/899 was obtained from Olabisi Onabanjo University Teaching Hospital, Ogun State, Nigeria.

\section{CONFLICT OF INTEREST}

None declared.

\section{REFERENCES}

1. National Agency for the Control of AIDS (NACA). National Strategic Framework on HIV and AIDS: 2017-2021. Available at: https://naca.gov. ng/wp-content/uploads/2017/09/NATIONAL-HIV-AND-AIDS-STRATEGICFRAMEWORK.pdf

2. World Health Organisation (WHO). World Malaria Report, 2018. Available at. https://www.who.int/malaria/publications/world-malaria-report-2018/ report/en/

3. Kwenti TE. Malaria and HIV coinfection in sub-Saharan Africa: prevalence, impact, and treatment strategies. Res Rep Trop Med. 2018;9:123-36.

4. World Health Organisation (WHO). Malaria in HIV/AIDS Patients. Geneva: WHO; 2017. Available at: https://www.who.int/malaria/areas/high_risk_ groups/hiv_aids_patients/en/

5. World Health Organisation (WHO). World Malaria Report 2015. Geneva: WHO; 2015. Available at: https://www.who.int/malaria/publications/worldmalaria-report-2015/report/en/

6. Kwenti TE, Kwenti TD, Latz A, Njunda LA, Nkuo-Akenji T. Epidemiological and clinical profile of paediatric malaria: a cross sectional study performed on febrile children in five epidemiological strata of malaria in Cameroon. BMC Infect Dis. 2017;17:499.

7. Joint United Nations Programme on HIV and AIDS. Fact sheet: World AIDS Day 2017. 2017. Available at: http://www.unaids.org/sites/ default/files/ media_asset/UNAIDS_FactSheet_en.pdf.

8. González R, Ataíde R, Naniche D, Menéndez C, Mayor A. HIV and malaria interactions: where do we stand? Expert Rev Anti Infect Ther. 2012;10:153-165.

9. Salako LA, Idigbe EO, Erinosho MA, Akinosho RO, Mafe AG. Malaria and Human Immunodeficiency Virus (HIV) infection among adults in Ogun State, South-Western Nigeria. Niger Quarterly J Hospital Med. 1996;6:279-283.

10. Cuadros DF, Branscum AJ, García-Ramos G. No evidence of association between HIV-1 and malaria in populations with low HIV-1 Prevalence. PLoS ONE. 2011;6: e23458.

11. Alemu A, Shiferaw Y, Addis Z, Mathewos B, Birhan W. Effect of malaria on HIV/AIDS transmission and progression. Parasites Vect. 2013;6:18.

12. French N, Nakiyingi J, Lugada E, Watera C, Whitworth JA, Gilks CF. Increasing rates of malarial fever with deteriorating immune status in HIV1-infected Ugandan adults. AIDS. 2001;15:899-906

13. Abu-Raddad LJ, Patnaik P, Kublin JG. Dual infection with HIV and malaria fuels the spread of both diseases in sub-Saharan Africa. Science. 2006:314:1603-1606.

14. Perrault SD, Hajek J, Zhong $\mathrm{K}$, et al. Human immunodeficiency virus coinfection increases placental parasite density and transplacental malaria transmission in Western Kenya. Am J Trop Med Hyg. 2009;80:119-125.

15. Kublin JG, Patnaik P, Jere CS, et al. Effect of Plasmodium falciparum malaria on concentration of HIV-1-RNA in the blood of adults in rural Malawi: a prospective cohort study. Lancet. 2005;365:233-240.

16. Mermin J, Lule JR, Ekwaru JP. Association between malaria and CD4 cell count decline among persons with HIV. J Acquir Immune Defic Syndr. 2006; 41:129-130.

17. Kamya MR. Effect of HIV-1 infection on antimalarial treatment outcomes in Uganda: a population-based study. J Infect Dis. 2000;193:9-15.

18. Omogunloye OG, Abiodun OE, Olunlade OA, Epuh EE, Asikolo I, Odumosu JO. Modeling malaria prevalence rate in Lagos state using multivariate environmental variations. Geoinformatics FCE CTU. 2018;17:61-86.

19. Ehiri JE, Alaofè HS, Yesufu V, et al. AIDS-related stigmatisation in the healthcare setting: a study of primary healthcare centres that provide services for prevention of mother-to-child transmission of HIV in Lagos, Nigeria. BMJ Open. 2019;9:e026322

20. Sanyaolu AO, Fagbenro-Beyioku AF, Oyibo WA, Badaru OS, Onyeabor OS, Nnaemeka Cl. Malaria and HIV co-infection and their effect on haemoglobin levels from three health-care institutions in Lagos, southwest Nigeria. Afr Health Sci. 2013;13:295-300.

21. Daniel WW. Biostatistics: a foundation for analysis in the health sciences. 7th ed. New York: John Wiley and Sons, 1999.

22. Oyeyemi OT, Sode OJ, Adebayo OD, Mensah-Agyei GO. Reliability of rapid diagnostic tests in diagnosing pregnancy and infant-associated malaria in Nigeria. J Inf Public Health. 2016:9:471-477.

23. Cheesbrough M. District Laboratory Practice in Tropical Countries, 2nd ed. Norfolk: Tropical Health Technology, 2009; p. 239-259.

24. Enya VNV, Idika N, Mafe AG, et al. Aetiology of fever among under-fives in Lagos, Nigeria. BMC Infect Dis. 2014;14:P42

25. Kolawole OM, Irekeola AA, Seriki AA, Bello KE. Investigation of risk factors associated with malaria and yellow fever coinfection among febrile patients in Ilorin, Nigeria. J Med Soc. 2018;32:33-39.

26. Adedotun AA, Salawu OT, Morenikeji OA, Odaibo AB. Plasmodial infection and haematological parameters in febrile patients in a hospital in Oyo town, South-western Nigeria. J Public Health Epidemiol. 2013;5:144-148.

27. Igharo EA, Osazuwa F, Ajayi SA, Ebueku A, Igbinigie O. Dual infection with typhoid and malaria in febrile patients in Ikare Akoko, Nigeria. Int J Trop Med. 2012;7:49-52

28. Ukaegbu CO, Nnachi AU, Mawak JD, Igwe CC. Incidence of concurrent malaria and typhoid fever infections in febrile patients in Jos, Plateau State Nigeria. Int J Sci Tech Res. 2014;3:157-161.

29. Singh S, Madaki AJ, Jiya NM, Singh R, Thacher TD. Predictors of malaria in febrile children in Sokoto, Nigeria. Niger Med J. 2014;55:480-485

30. Ayorinde AF, Oyeyiga AM, Nosegbe NO, Folarin OA. A survey of malaria and some arboviral infections among suspected febrile patients visiting a health centre in Simawa, Ogun State, Nigeria. J Inf Public Health. 2016:9:52-59.

31. Jemimah Y, Victor O, Elizabeth A, Akpu P, Lynda A. Plasmodium falciparum infection among febrile patients attending a tertiary healthcare facility in Central Nigeria: prevalence, hematologic and sociodemographic factors. Int J Trop Dis. 2019;2:1-6.

32. Michael GC, Aliyu I, Idris U, et al. Investigation of malaria by microscopy among febrile outpatients of a semi-rural Nigerian medical center: what happened to malaria control programs? Niger J Gen Pract. 2019;17:23-30.

33. Osunkiyesi, M. The road to 2020: mobilising the private sector in Nigeria's fight against malaria - the Lagos State approach. Presented at the 2015 CAMA Annual Technical Forum.

34. Israel OK, Fawole OI, Adebowale AS, et al. Caregivers' knowledge and utilization of long-lasting insecticidal nets among under-five children in Osun State, Southwest, Nigeria. Malar J. 2018:17:231.

35. Omonijo A, Omonijo AO. Assessment of the status of awareness, ownership, and usage of long-lasting insecticide treated nets after mass distribution in Ekiti State, Nigeria. J Parasitol Res. 2019:1273714.

36. Wright KO, Tayo F, Odusanya OO, et al. Perception and practices of Lagos state residents on the prevention and control of malaria in Lagos, Nigeria. Ann Trop Med Public Health. 2013;6:503-507.

37. Umolu Pl, Okoror LE, Orhue P. Human immunodeficiency virus (HIV) seropositivity and hepatitis B surface antigenemia (HBSAG) among blood donors in Benin City, Edo state, Nigeria. Afr Health Sci. 2005;5:55-58.

38. Motayo BO, Faneye AO, Udo UA, Olusola BA, Ezeani I, Ogiogwa JI. Seroprevalence of transfusion transmissible infections (TTI), in first time blood donors in Abeokuta, Nigeria. Afr Health Sci. 2015;15:19-25.

39. Onoja A, Mohammed SB, Ya'aba Y, Liman M, Njab J. Seroprevalence of HIV among the people of Lake Chad Basin of Borno State, Nigeria. JOPAT. 2016;15:31-39

40. Simon M, Anyebe EE, Ojo CO, Ankuma, SJ. Prevalence of HIV among pregnant women attending antenatal clinic in a teaching hospital in Northwest Nigeria. West Afr J Nursing. 2016;27:56-74.

41. Kalyesubula I, Musoke-Mudido P, Marum L, et al. Effects of malaria infection in human immunodeficiency virus type 1-infected Ugandan children. Pediatr Infect Dis J. 1997;16:876-881.

42. Chandramohan D, Greenwood BM. Is there an interaction between human immunodeficiency virus and Plasmodium falciparum? Int J Epidemiol. 1998:27:296-301.

43. Kamya MR, Gasasira AF, Yeka A, et al. Effect of HIV1 infection on antimalarial treatment outcomes in Uganda: a population-based study. $J$ Infect Dis. 2006;193:9-15. 